\title{
Physical Rehabilitation Program to Improve the Physical and Functional Status after Hospitalization of Open-Heart Surgery
}

\author{
Waleed Abd el Fattah Fahmy Mahmoud*
}

Alexandria University, Alexandria, Egypt

Received: 8 June, 2017; Accepted: 06 September, 2017; Published: 25 September, 2017

*Corresponding author: Waleed Abd el Fattah Fahmy Mahmoud, Alexandria University, Alexandria, Egypt, Tel:00201006194553; E-mail: dr.waleed.fahmy32@gmail.com

\begin{abstract}
This research aims to help speed of the healing of the sternum and the muscles working on it. As well as improved functional status and physical rib cage muscles affected by open-heart surgery. The reduction of pain associated with movements of the patient. Raise the efficiency of the heart muscle after surgery and this study was conducted on a sample of 100 individuals who underwent open-heart surgery where the number of those excluded from the sample 86 per person and those who were not attending the meetings and for several reasons, especially belonging geographical location and the high cost of mobility and movement and their inability to afford such burdens., Bringing the total number of sample 14 persons, of whom nine members of the experimental group and 5 members of the group officer.
\end{abstract}

The researcher used the experimental method to the suitability of the nature of the study and their objective where the program was designed and put its own axes.

The most important results to the disappearance of the patient's pain and healing of the sternum during the first three weeks of the surgery, which track out of intensive care., That physiotherapy equipment (tens current - lasers- ultrasound) a significant effect on the healing of the sternum and the disappearance of pain during the first three weeks immediately after surgery. The return of natural rubber for the muscles of the neck, abdomen and chest as well as muscle strength to lift the muscles of the neck, abdomen and chest and increase the power and efficiency of the heart muscle.

Therefore, the researcher recommended the need for the application of physiotherapy equipment (tens current- lasers and ultrasound) in patients after open heart surgery. Must be adhered to the position right to put Alaketruat own device tens, should also start implementing the program immediately exit the patient from the intensive care unit, start using physiotherapy apparatus according to each case to an end and the extent of its stability., Be labeled diagnostic for such cases that apply Find the problem and this type of surgery Egypt Cardiac Rehabilitation short (ECR) due to the difference between them and the Cardiac Rehabilitation (CR), the application of this program to all cases of open heart surgery to whether valves or arteries or hole in the heart or congenital defects and its importance.

Keywords: Physical rehabilitation program; functional status; open heart surgery; hospitalization; Tens; Current ;Ultrasound therapy; Laser

\section{Introduction}

Most historians mention that the year 1938 is the beginning of the era of modern heart surgery, where the US surgeon Gross binds to the arterial canal successfully, but remained openheart operations await the development of ways to reduce body temperature and the development of artificial heart and lung machine where it happened at the hands of Bigelow, Gibbon. The first open heart operation was performed to close the aperture between the atria in 1953, followed by the repair of a number of congenital heart defects. , Starr also conducted the first valve switch operation in 1961, and then Barnard conducted the first heart transplant in 1967.

Most open-heart operations are carried out through the incision of the sternum longitudinally in the middle of 8-10 inches in the direction of the Mediterranean line starting from the top of the sternum to the top of the umbilical cord slot containing the sternum and rib cartilages and muscles that take these origins places and Andgamat like her (pectoralis major muscle - pectoralis minor muscle- sternocleidomastoid muscle- external oblique muscle- internal oblique muscle - rectus abdominis muscle- transverse abdominis muscle - Subclavius muscleSerratus anterior muscle) $[10,20]$ (Figure 1).

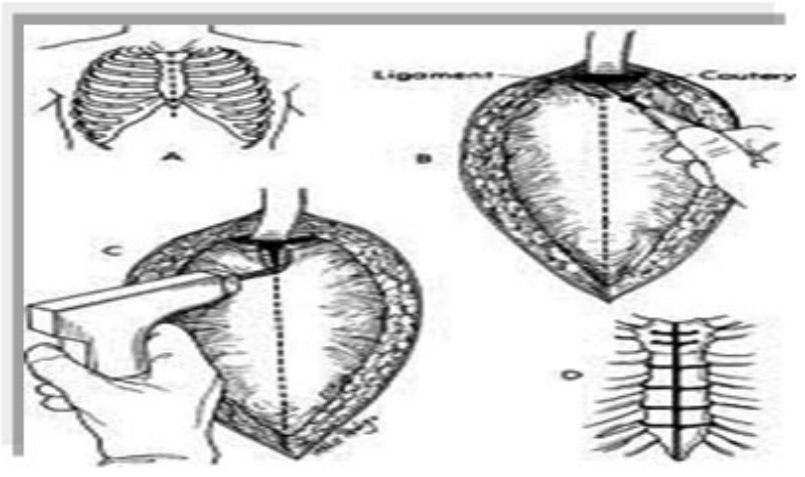

Figure 1: Chest incision during open heart surgery 
Because this section allows the surgeon access to the heart and the walls where the patient is placed on the heart and lung device so that the surgeon can work directly on the heart and when the completion of the surgery back to the heart to work on its own after the heart and lung is stopped and then closed the bone of the cut and installed from And the skin is closed by stitches, pins or glue, according to the surgeon's preference, the sutures are removed within 7-14 days of surgery, but the metal wires remain in the shear bone as they are and are not removed [26] (Figure 2).

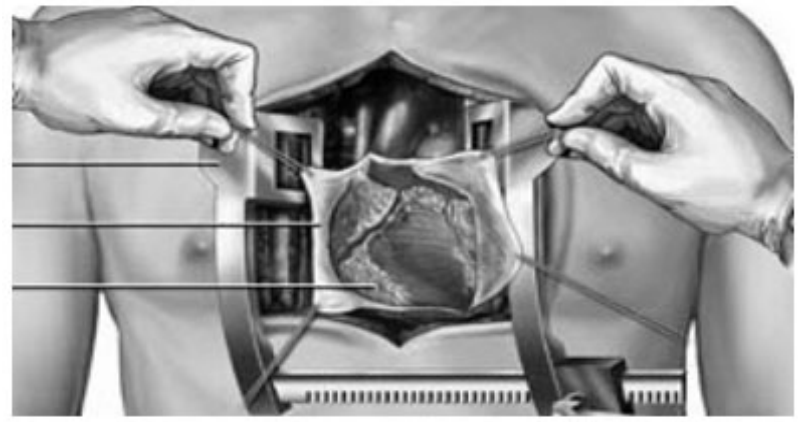

Figure 2: Surgical opening of the heart

However, some heart operations can be performed by crossstitching in the left or right chest wall. A number of surgeons have recently sought to perform heart operations through microincisions that allow the insertion of endoscopy devices and special instruments used directly on the heart.

The Naser Institute for Research and Therapy explains the Cardiac Surgery Unit (2006): The patient is suffering from burns and fatigue, which is a natural symptom but does not suffer from severe pain. It is useful to perform exercises for the movement of the arms and shoulders. As directed by your doctor

The patient must start his activity as soon as possible after the surgery by doing some light exercises and moving the body in bed and gradually will ask the patient to sit on the chair and then walk. The type of movement required will be decided according to each patient separately and under the guidance of the doctor.

As for sleep conditions, sleep on the back and help at the beginning of entry to or out of bed so as not to load the entire body weight on the patient's arm, which affects the healing bone cut.

After one or two days, the lid is removed from the chest wound and left exposed to the air to dry and the stitches are removed within one to two weeks without pain after the surgery, as the case is, and the shear bone is cured about six weeks after surgery and during this period The doctor may prescribe a thoracic belt to put the patient around the chest to reduce the movement of the shear bone during this period to give her the chance to heal naturally [23].

The patient may feel pain at the site of the wound (shear bone) when breathing deeply or coughing. This requires giving the patient medicines to help control the pain. The patient also feels dry mouth and sore throat due to the breathing tube used in surgery [14].

Health Sciences Foundation, Hamilton (2006) stated that the patient should be given a medical belt for the front muscles of the chest and returned by the patient for at least three months after surgery.

The shear bone begins to heal from 6 to 8 weeks after surgery, but it can take up to six months to fully heal. There are also some symptoms associated with the patient on the surface of the chest at the site of surgery, such as the presence of itching or prick along the opening of the surgery, the patient feels excess sensitivity, and feels as if he has sunburns on his skin at the site of surgery [14].

During this period, the patient is advised not to lift, push or pull anything heavier than $2-4.5 \mathrm{~kg}$. It is also recommended not to extend the arms over the head. , Hug a pillow or blanket while breathing deeply or cough to support the chest as needed [14, 27].

Also do not carry young children or pets for 8 weeks and avoid bending forward. , And avoid placing the arm behind the shirt. , And avoid sitting for a long time on a chair without armrests. Also, avoid using only one arm, and refrain from engaging in violent sports activities such as golf, tens current and swimming for at least 8 weeks. , As you should avoid walking on uneven ground or beach for 4-6 weeks [27].

Both Wong \& bozinovski (2011) note that the patient is not allowed to rush and start driving after 6-8 weeks of surgery and after the cardiologist's permission is reviewed. , And wear a seat belt at all times, especially during long trips, stop every hour and extend the legs to prevent clotting.

It is also necessary to stop work for 6-12 weeks and only return to work with the consent of the surgeon, and this is determined according to the type of work performed by the patient [27].

William A Baumgartner \& DukeE Cameron (2009) After the surgery, the patient feels good days and bad days as the patient experiences a lot of different feelings due to lack of sleep, low activity and physical pain resulting from the surgery leading to feelings of depression and insomnia which usually occur during the first weeks As well as difficulty concentrating during the first or second week of surgery. The patient also feels chest tightness and difficulty sleeping at night [26].

The British Heart Foundation (2013) reported that the shear bone takes 10 to 12 weeks after surgery to heal. [5].

Thomassv \& Toddk.Rosengart (2009) noted that pain can be exacerbated when getting out of bed, walking or breathing exercises, and here the patient should take painkillers prescribed for pain. They also pointed out that pain medication can cause in constipation or drowsiness or feeling sick [25].

Some patients who have undergone open heart surgery have some patients who suffer from difficulty in the movement of the thoracic cage and also difficulty in sleep. They are asked not to 
sleep on both sides during the recovery period for fear of a hernia. Therefore, the patient is always required to sleep on the back. It may take weeks or months leading to boredom and fatigue and after the healing bone cut is still suffering from the patient in the area of the rib cage, especially when sleeping on the sides and shortness in the range of motor thoracic and the muscles working on it and continue this even after surgery a year and a half and two years.

\section{Research Importance}

There is no doubt that after open heart surgery, this will have a negative impact on the physical and functional efficiency of the patient in general and on the efficiency of the chest and upper extremity in particular and vary in terms of intensity and time period from person to person. , And this may necessitate the researcher's attempt to develop a physical rehabilitation program to improve the functional and physical condition after hospitalization of open heart surgery.

\section{Research Goals}

Designing a qualifying program aimed at:

- Help to accelerate the healing of the shear bone and muscles working on it.

- Reduce the pain associated with the movements of the patient (chest).

-Improve the functional and physical condition of the affected thoracic muscles of open heart surgery.

-Improve the efficiency of the heart muscle after surgery.

\section{Search questions}

-Does the program accelerate the process of healing the shear strength of the patient after open heart surgery compared to the control group?

-Does the program reduce the pain experienced by the patient after open heart surgery compared to the control group?

-Are there any statistically significant differences in the functional measurements under study for the thorax of the affected thoracic muscle before and after the program of the experimental group?

-Are there any significant differences in the physical measurements represented in the strength and elasticity of muscles affected by surgery before and after the program of the experimental group?

-Are there any statistically significant differences in the efficiency of the heart muscle before and after the program of the experimental group?

-Are there any differences of statistical significance in the functional and physical measurements under study after the program between the experimental and control groups?

\section{Search terms}

\section{Procedural definition of the title of the research}

The researcher explains the difference between the term hospitalization in the title of the research and the term recovery of recovery for the subjects of the sample subject of the study where:

The term healing: - In the Arabic language means seeking healing, and a hospital in the matter means to treat it.

Some patients have problems with valves or arteries or congenital defects and others, requiring hospitalization by medical intervention or surgical operation, and in the case of surgical intervention requires intervention programs rehabilitation to recover healing, not to.

The term healing recovery means revitalizing, renewing, improving, strengthening, compensating and rebuilding for a period of time until reaching the level of the individual.

This concept emphasizes the difference in English between the two terms, as the term hospitalization refers to the term "recovery".

Rehabilitation: is the process by which the various therapeutic means are used to return the injured person to perform his normal activity, which does not allow the recurrence of the injury [22].

Functional status: The extent to which changes in body functions are due to the performance of physical pregnancy [28].

Physical condition: The extent to which the various organs of the body can bear the burdens and activities of everyday life [8].

\section{Search procedures}

\section{Research Methodology}

The experimental approach was chosen to suit the nature and purpose of the study.

\section{Research fields}

-The human field: The sample was selected from patients who underwent open heart surgery, after taking the approval of the Ethics -Committee of the Faculty of Medicine - Zagazig University and taking the written consent of each patient, without specifying a particular class or a certain Sunni stage. , Was excluded from diabetics, and those who use industrial organizations.

-Time domain: The study was conducted during the period from $25 / 11 / 2012$ to $30 / 12 / 2013$

-Geographical area: Cardiology and chest surgery hospital, Faculty of Medicine Department of Cardio-Thoracic Surgery, Outpatient Clinic, Faculty of Medicine Department of Rheumatism and Rehabilitation Zagazig University. 


\section{The research sample}

The total sample size at the beginning of the study was 100 individuals who underwent open heart surgery. , And the number of those excluded from the sample was 86 individuals and those who were not regular in the meetings for several reasons, especially the geographical affiliation and the high cost of movement and movement. The vast majority of the samples were from cities and villages far from the city of Zagazig such as Ismailia and Abu Hammad and others, Patients have to bear such high costs, especially the burdens of travel and the burden of the road and they are still in the period of purity. The period of time for the application of the research was full of many problems such as demonstrations, roadblocks, strikes and other factors that helped leak the sample, $\mathrm{H}$ total number of sample 14 individuals including 9 members of experimental group and 5 members of a control group.

\section{Survey Study}

The exploratory study relied on the researcher's experience through his work in the field of physiotherapy and rehabilitation and accompanying these patients in many hospitals and major centers specialized in open heart surgery such as Ain Shams Specialist Hospital, Nasser Institute Hospital, Zagazig University Hospital. , Where the direct contact with these patients and his suffering and their follow-up to them. , And this contributed to identify the most important problems suffered by the patient after open heart surgery. . The researcher also conducted a comprehensive survey of Arabic and foreign studies around the world to find out the latest methods and methods of rehabilitation and problems facing patients after open heart surgery. The study started from 20/3/2007 till 20/11/2012.

\section{Preparation for study}

The training program was presented to specialists in the field of cardiothoracic surgery and to specialists in physiotherapy and rehabilitation. The program was also approved before the Faculty of Medicine Zagazig University Department of Cardio-Thoracic Surgery and the Department of Rheumatism and Rehabilitation.

\section{Tools and devices used in data collection}

-Tape centimeter

-Balls (Rsfllo)

-Adhesive tape

-Echocardiography

-Antiseptic disinfectant

-Check bed

-Iron bar

-Various weight weights

\section{Tools and devices used in rehabilitation}

-Ultrasound-therapy device

- Tens current
-Laser therapy

-Bed checked

-Iron bar

-Various weight weights

\section{Functional and physical measurements}

First: functional measurements

Respiratory efficiency measurement

Breathing apparatus (Respiflo) (Ball machine) (Figure 3).

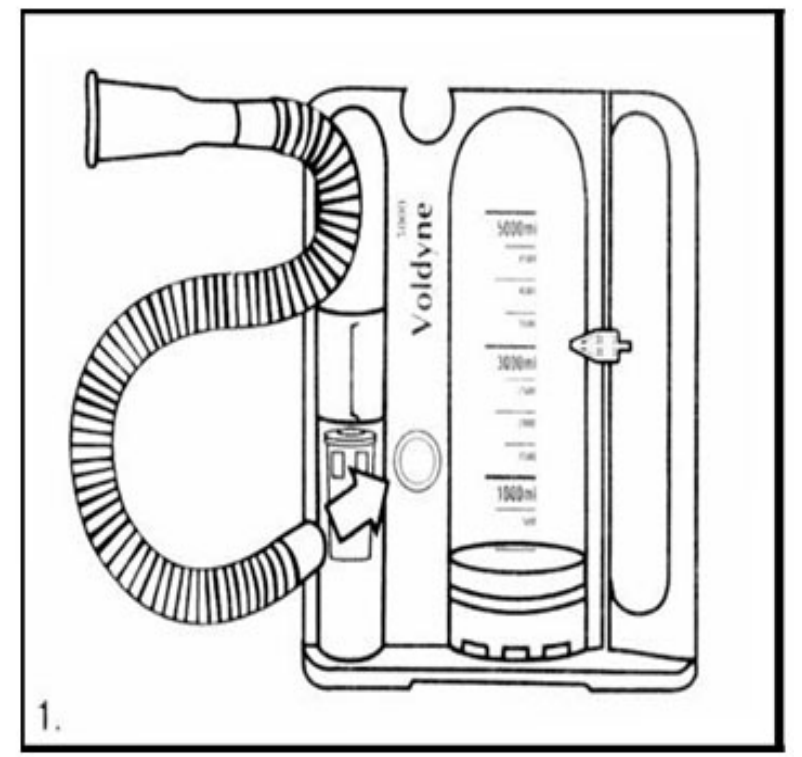

Figure 3: RSPFLU

\section{Measuring the strength of the heart muscle}

-Echocardiograph

-Journey of Inhalation and exhalation (chest circumference) [1] (Figure 4 and 5).

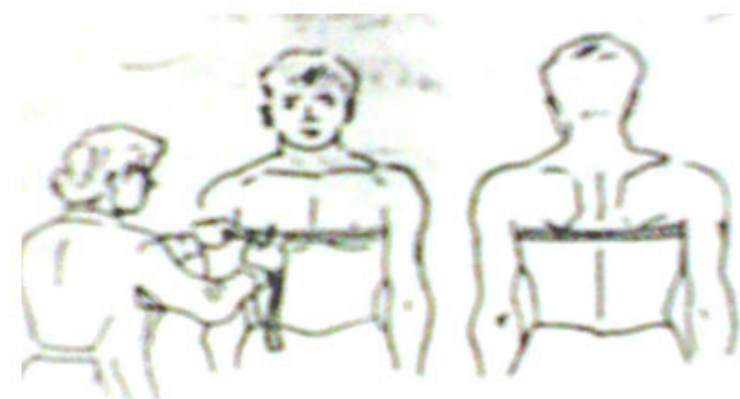

Figure 4: Journey of Inhalation and Exhalation 


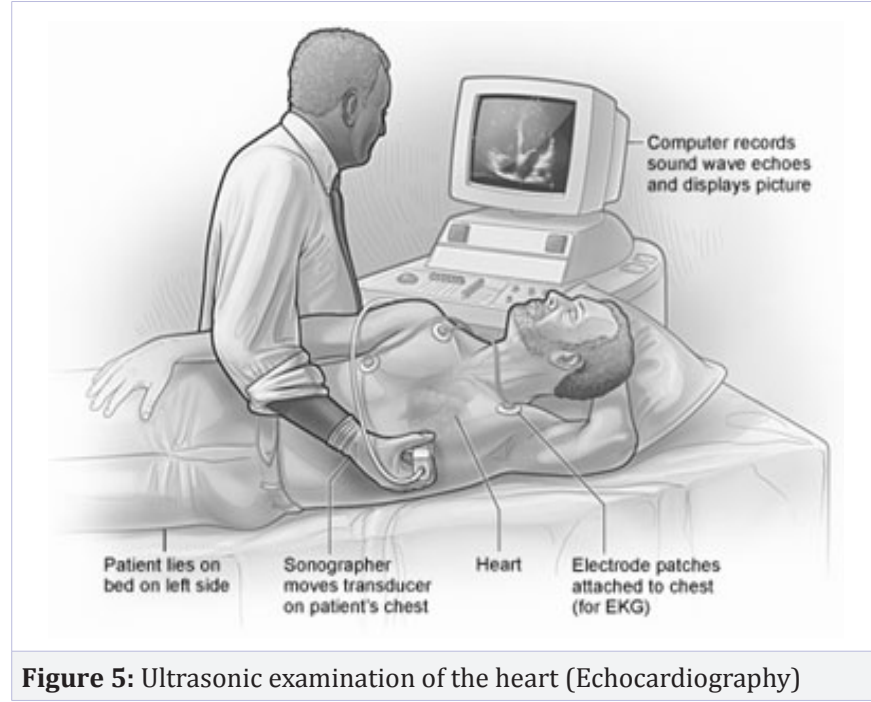

\section{Physical measurements}

-Muscle rubber measurement: Rubber gauge of the muscles: Test the rubber of the dorsal position (Figure 6).

-Rubber gauge of chest muscles: Test the rubber of the supine position (Figure 7).

-Measurement of elastic abdominal muscles: Test the torsion movement in the spine (Figure 8)

-General rubber gauge for the upper part: Measure the movement of the spine around the vertical axis [19] (Figure 9).

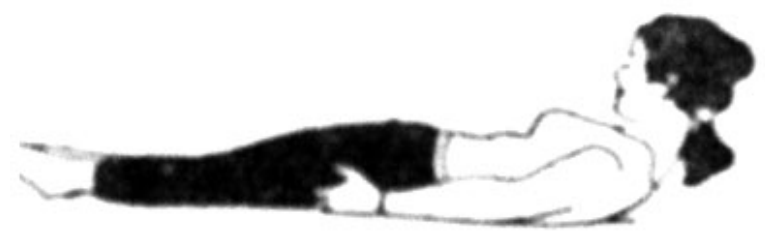

Figure 6: Natural Rubber for Neck Muscle

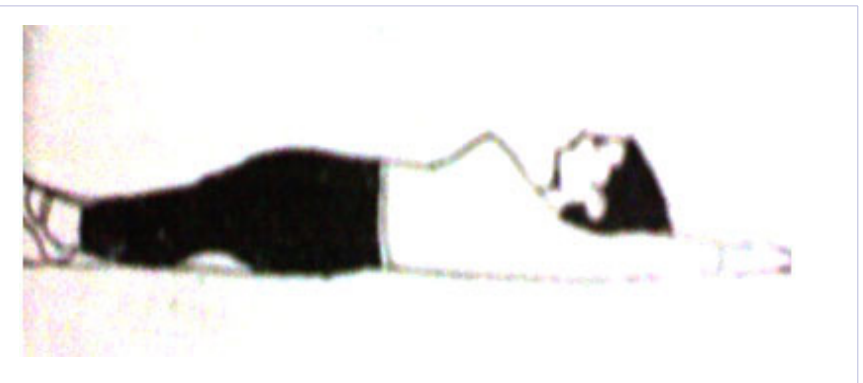

Figure 7: Natural Inflammation of Chest Muscle
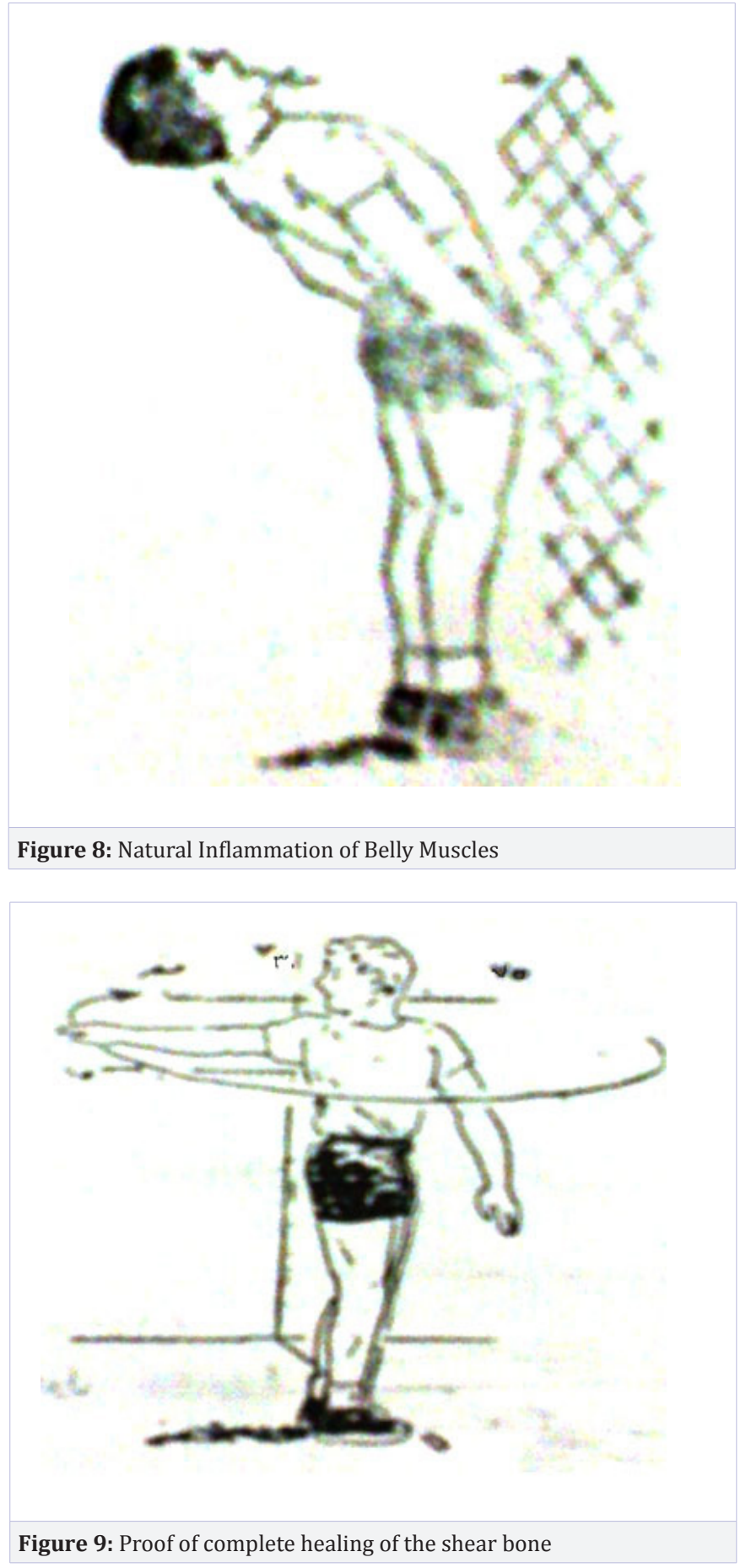

Measurement of muscle strength

-Measure the muscle strength of the neck muscles: Test the power of the laying position.

-Measure the muscle strength of the abdominal muscles: Test the sitting of the supine position of the D-legs (Figure 10). 

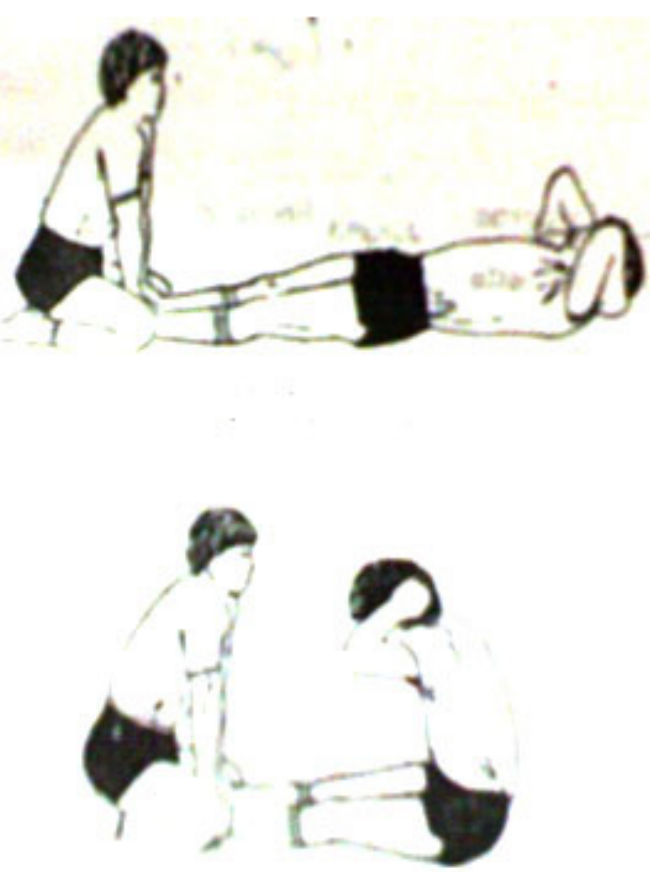

Figure 10: Muscle strength of the abdominal muscles

\section{Third: Interim measurements}

-Measuring the degree of pain: Through the pain regulator (Figure 11).

-Measurement of pain (clinical).

-Measuring the speed of healing: (clinical).

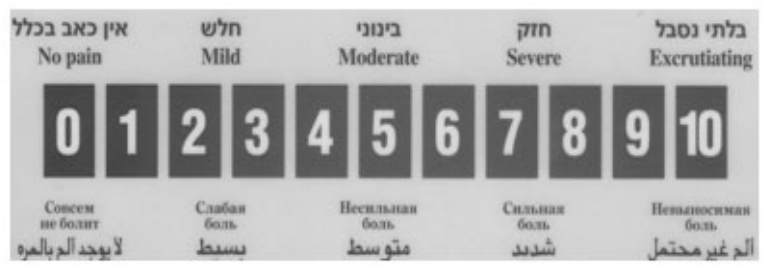

Figure 11: Ruler pain

\section{The importance of the program}

-Introducing weight training in rehabilitation after open heart surgery.

-The use of physiotherapy equipment in rehabilitation after open heart surgery.

-Determining the correct place to place the electrodes of the device (tens current).

-Develop a diagnostic name for such cases.

\section{Program content}

-Rehabilitation exercises are the basis of the components of the rehabilitation program, as well as some natural remedies such as:
-Tens Current (Figure 12)

-Ultrasound- therapy (Figure 13)

-Laser Therapy (Figure 14)

The program is applied after the exit from intensive care as a unit of three sessions a week. The application of physical therapy once the patient's condition is confirmed by the cardiologist.

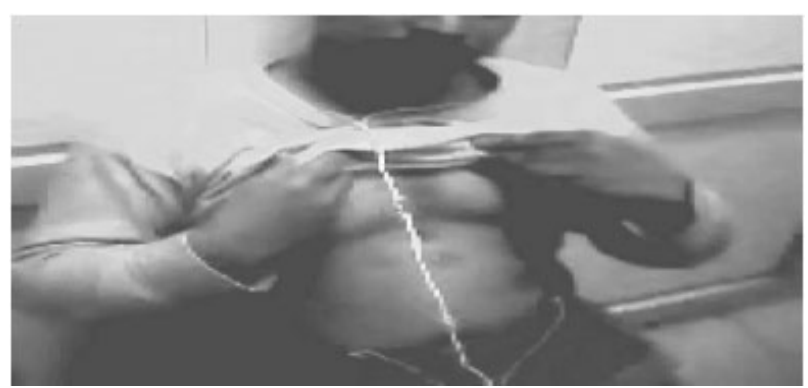

Figure 12: One of the patients during treatment with Tens Current after open heart surgery

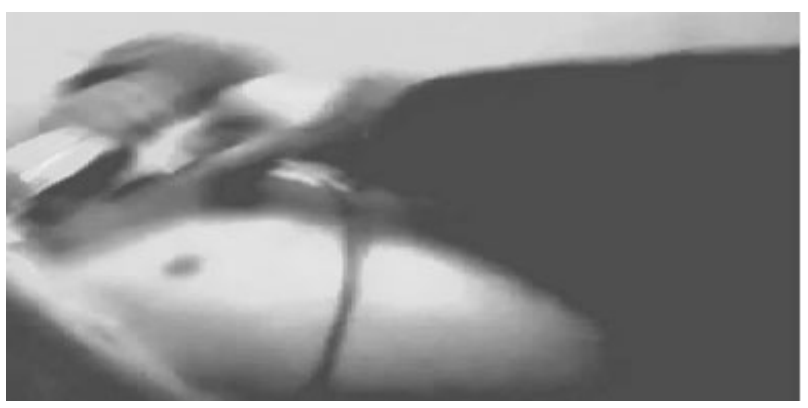

Figure 13: One patient during ultrasound therapy after open heart surgery

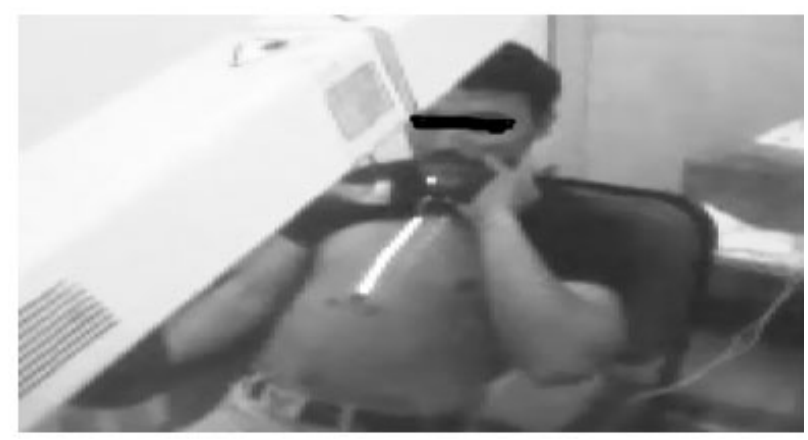

Figure 14: One patient during laser therapy after open heart surgery

\section{Objective of using natural remedies}

-Work on the speed of healing.

-Reduce the pain resulting from the surgical effect 


\section{The aim of using rehabilitation exercises}

-Provide the affected area fitness elements

-The speed of the patient's return to normal

\section{Application of the program}

\section{First, the experimental group}

The program was applied to experimental subjects only after they were taken out of intensive care directly for one month. The intermediate measurements were applied three weeks after the application of the program to the members of the experimental group to confirm the healing of the shear bone and the disappearance of pain. $=0$ and the degree of healing was $100 \%$. The measurements showed no different degrees of measurement after this period and functional and physical measurements were applied to the experimental sample after the end of the program.

\section{Second control group}

The researcher was unable to apply functional and physical measurements to the members of this group after the deadline for the application of the program to the members of the experimental group because of the lack of healing in the control group during this period. The severity of the shear is not cured, and therefore the severity of the shear bone may be exposed if such measurements are applied before healing. , So the measurements applied to this group are measurements immediately prior to surgery.

\section{Statistical treatments that have been used}

-Arithmetic mean

-Standard deviation

\section{-Differences}

-As well as the percentage\% for the improvement of the sample members of the Before and After measurement of the experimental group only.

\section{Results}

Table 1 shows the number of males in the experimental group at 2 , and the number of females is 7 . The number of males in the control group is 2 individuals, and the number of females 3 individuals.

The experimental group included 3 individuals who underwent valve replacement surgery, 3 underwent valve replacement surgery, 2 underwent valve replacement surgery and 1 repair, and 1 underwent heart surgery. , And the control group included 2 individuals who underwent surgery to change two valves. , 1 individual to change the arteries of the heart. 1 individual to change the two valves and repair the third. 1 person underwent Heart hole surgery.

As shown in table 2 for the homogeneity of the data of the research sample in the basic primary measurements, the torsion coefficients ranged from $(-0.49$ to 1.38$)$ indicating that the measurements obtained are close to moderation. The values of

\begin{tabular}{|c|c|c|c|}
\hline The group & $\begin{array}{c}\text { Status } \\
\text { number }\end{array}$ & Sex & Type of surgical operation \\
\hline \multirow{10}{*}{ Experimental } & 1 & Female & Atrial septal defect \\
\hline & 2 & Male & Change valve \\
\hline & 3 & Female & $\begin{array}{c}\text { Valve change and other } \\
\text { repair }\end{array}$ \\
\hline & 4 & Female & Change valve \\
\hline & 5 & Female & Change two valves \\
\hline & 6 & Female & $\begin{array}{c}\text { Valve change and other } \\
\text { repair }\end{array}$ \\
\hline & 7 & Female & Change two valves \\
\hline & 8 & Male & Change valves \\
\hline & 9 & Female & Change two valves \\
\hline & 1 & Male & Arteries \\
\hline \multirow{4}{*}{ Control } & 2 & Female & Change two valves \\
\hline & 3 & Female & Atrial septal defect \\
\hline & 4 & Male & Change two valves \\
\hline & 5 & Female & $\begin{array}{c}\text { Change two valves and fix } \\
\text { the third }\end{array}$ \\
\hline
\end{tabular}

the mean torsion coefficient are between \pm 3 and close to zero which confirms the homogeneity of the experimental and control group members and the total group in the initial variables before the experiment.

Table 3 shows the differences between the experimental group and the control group in (basic primary measurements). That the value of $(\mathrm{T})$ calculated ranged between $(0.57-1.41)$ and these values are not significant at the level of 0.05 , which indicates the absence of significant differences between the two groups and confirm that there is equivalence between the two sets of research in the primary measurements.

Table 4 shows the homogeneity of the research sample data in functional measurements prior to the experiment. (0.08 $0.53)$, indicating that the measurements obtained are close to moderation. The values of the mean spindle are between \pm 3 and close to zero. This confirms the homogeneity of the experimental and control group members and the total group in the functional measurements before the experiment.

Table 5 shows the homogeneity of the research sample data in physical measurements before the experiment. (0.04 to 1.94 ) indicating that the measurements obtained are close to moderation. The values of the mean spindle are between \pm 3 and close to zero. This confirms the homogeneity of the experimental and control group members and the total group in the physical measurements before the experiment. 
Table 2: Statistical description of the sample data (experimental, control and total group) in the basic primary variables before the experiment

\begin{tabular}{|c|c|c|c|c|c|c|}
\hline Variables & \multirow[b]{2}{*}{ Groups } & \multirow[b]{2}{*}{ Number $\mathbf{n}$} & \multicolumn{4}{|c|}{ Statistical Significance of Characterization } \\
\hline \multirow{4}{*}{ Age } & & & Arithmetic mean & Median & $\begin{array}{l}\text { Standard } \\
\text { deviation }\end{array}$ & $\begin{array}{c}\text { Torsion } \\
\text { coefficient }\end{array}$ \\
\hline & Experimental & 9 & 35.78 & 37 & 6.08 & 0.78 \\
\hline & Control & 5 & 41 & 44 & 10.61 & 1.66 \\
\hline & Total Research Group & 14 & 37.64 & 40 & 8.01 & 0.49 \\
\hline \multirow{3}{*}{ Length } & Experimental & 9 & 161.22 & 163 & 6.53 & 1.31 \\
\hline & Control & 5 & 156.4 & 160 & 5.9 & 0.52 \\
\hline & Total Research Group & 14 & 159.5 & 160 & 6.54 & 0.69 \\
\hline \multirow{3}{*}{ The weight } & Experimental & 9 & 69.72 & 65 & 13.43 & 1.6 \\
\hline & Control & 5 & 66.2 & 66 & 9.68 & 0.34 \\
\hline & Total Research Group & 14 & 68.46 & 65 & 11.95 & 1.38 \\
\hline
\end{tabular}

Table 3: Differences between the experimental group and the control group in the initial measurements before the experiment (equivalence)

\begin{tabular}{|c|c|c|c|c|c|c|}
\hline \multirow{2}{*}{ Stastical Significance } & \multicolumn{2}{|c|}{$\begin{array}{l}\text { The Experimental group } \\
\qquad \mathrm{N}=9\end{array}$} & \multicolumn{2}{|c|}{$\begin{array}{l}\text { Control group } \\
\qquad \mathbf{N}=\mathbf{5}\end{array}$} & \multirow{2}{*}{$\begin{array}{c}\text { The difference } \\
\text { between } \\
\text { the two } \\
\text { averages }\end{array}$} & \multirow{2}{*}{$\begin{array}{l}\text { Values } \\
\qquad \mathbf{T}\end{array}$} \\
\hline & $x$ & $\Sigma$ & $x$ & $\Sigma$ & & \\
\hline Age & 35.38 & 6.08 & 41 & 10.61 & 5.22 & 1.01 \\
\hline Length & 161.22 & 6.53 & 156.4 & 5.9 & 4.82 & 1.41 \\
\hline The weight & 69.72 & 13.43 & 66.2 & 9.68 & 3.52 & 0.57 \\
\hline
\end{tabular}

\begin{tabular}{|c|c|c|c|c|c|c|c|c|}
\hline \multirow[b]{2}{*}{ No } & \multirow{2}{*}{\multicolumn{2}{|c|}{ Functional measurements }} & \multirow[b]{2}{*}{ Groups } & \multirow[b]{2}{*}{ Number $n$} & \multicolumn{4}{|c|}{ Statistical significance of the description } \\
\hline & & & & & $\begin{array}{l}\text { arithmetic } \\
\text { mean }\end{array}$ & median & Standard & $\begin{array}{c}\text { Torsion } \\
\text { coefficient }\end{array}$ \\
\hline \multirow{3}{*}{1} & \multirow{3}{*}{\multicolumn{2}{|c|}{$\begin{array}{l}\text { The journey of the inspiration and exhalation, the difference } \\
\text { between the maximum of inspiration and maximum exhalation }\end{array}$}} & Experimental & 9 & 2.11 & 2 & 0.93 & 0.94 \\
\hline & & & Control & 5 & 2.2 & 2 & 0.84 & $0.51-$ \\
\hline & & & $\begin{array}{l}\text { Total Research } \\
\text { Group }\end{array}$ & 14 & 2.14 & 2 & 0.86 & 0.53 \\
\hline \multirow{5}{*}{2} & \multirow{3}{*}{\multicolumn{2}{|c|}{$\begin{array}{c}\text { RSPFLO } \\
\text { device } \\
\text { To assess the } \\
\text { efficiency }\end{array}$}} & Experimental & 9 & 966.67 & 900 & 200 & $0.25-$ \\
\hline & & & Control & 5 & 102 & 1200 & 268.33 & $1.26-$ \\
\hline & & & $\begin{array}{l}\text { Total Research } \\
\text { Group }\end{array}$ & 14 & 985.71 & 900 & 217.88 & $0.52-$ \\
\hline & \multirow{2}{*}{$\begin{array}{l}\text { of the } \\
\text { respiratory } \\
\text { system }\end{array}$} & \multirow{2}{*}{ Inflation } & Experimental & 9 & 811.11 & 900 & 220.48 & 1.98- \\
\hline & & & $\begin{array}{l}\text { Total Research } \\
\text { Group }\end{array}$ & 14 & 842.86 & 900 & 213.81 & $1.26-$ \\
\hline \multirow{3}{*}{3} & \multirow{3}{*}{\multicolumn{2}{|c|}{ The strength of the heart muscle (Ultra sound scan on the heart ) }} & Experimental & 9 & 65.11 & 64 & 6.58 & 0 \\
\hline & & & Control & 5 & 65 & 64 & 7.78 & $0.24-$ \\
\hline & & & $\begin{array}{c}\text { Total Research } \\
\text { Group }\end{array}$ & 14 & 65.07 & 64 & 6.73 & $0.08-$ \\
\hline
\end{tabular}

Citation: Waleed Abd el Fattah Fahmy Mahmoud (2017) Physical Rehabilitation Program to Improve the Physical and Functional Page 8 of 17 Status after Hospitalization of Open-Heart Surgery. J Cardiovascular Thoracic Surgery 3(1):1-17. 


\begin{tabular}{|c|c|c|c|c|c|c|c|c|}
\hline \multirow[b]{2}{*}{ No } & \multirow{2}{*}{\multicolumn{2}{|c|}{ Physical measurements }} & \multirow[b]{2}{*}{ Groups } & \multirow{2}{*}{ Numbers } & \multicolumn{4}{|c|}{ statistical significance of the description } \\
\hline & & & & & $\begin{array}{l}\text { Arithmetic } \\
\quad \text { Mean }\end{array}$ & Median & $\begin{array}{l}\text { Standard } \\
\text { deviation }\end{array}$ & $\begin{array}{c}\text { Torsion } \\
\text { coefficient }\end{array}$ \\
\hline \multirow{3}{*}{1} & \multirow{3}{*}{\multicolumn{2}{|c|}{$\begin{array}{l}\text { Measure the natural elasticity of the neck muscles } \\
\text { degrees } 10\end{array}$}} & Experimental & 9 & 8.72 & 10 & 2.22 & $1.65-$ \\
\hline & & & Control & 5 & 9.4 & 10 & 1.34 & $1.24-$ \\
\hline & & & $\begin{array}{l}\text { Total Research } \\
\text { Group }\end{array}$ & 14 & 8.96 & 10 & 1.93 & $1.82-$ \\
\hline \multirow{3}{*}{2} & \multirow{3}{*}{\multicolumn{2}{|c|}{$\begin{array}{c}\text { Measure the natural elasticity of the chest muscles. } \\
\text { The arms are elongated, replacing their integrity. } \\
\text { Degree } 180\end{array}$}} & Experimental & 9 & 176.11 & 180 & 1.83 & 1.93- \\
\hline & & & Control & 5 & 180 & 180 & 0 & 0 \\
\hline & & & $\begin{array}{c}\text { Total Research } \\
\text { Group }\end{array}$ & 14 & 179.43 & 180 & 1.5 & $1.61-$ \\
\hline \multirow{3}{*}{3} & \multirow{3}{*}{\multicolumn{2}{|c|}{$\begin{array}{l}\text { Measure the natural elasticity of the abdominal } \\
\text { muscles (measuring the extent of the movement of } \\
\text { the torso in the spine) }\end{array}$}} & Experimental & 9 & 59 & 61 & 17.18 & 1.33 \\
\hline & & & Control & 5 & 73 & 73 & 22.81 & 0.88 \\
\hline & & & $\begin{array}{l}\text { Total Research } \\
\text { Group }\end{array}$ & 14 & 64 & 62 & 19.75 & 1.05 \\
\hline \multirow{6}{*}{4} & \multirow{6}{*}{$\begin{array}{l}\text { the dynamic } \\
\text { range of the } \\
\text { spine around } \\
\text { the vertical } \\
\text { axis }\end{array}$} & \multirow{3}{*}{ The right part } & Experimental & 9 & 19.33 & 20 & 15.26 & 0.08 \\
\hline & & & Control & 5 & 15.4 & 13 & 9.04 & 0.32 \\
\hline & & & $\begin{array}{c}\text { Total Research } \\
\text { Group }\end{array}$ & 14 & 17.93 & 16.5 & 13.12 & 0.3 \\
\hline & & \multirow{3}{*}{ The left part } & Experimental & 9 & 23.44 & 27 & 10.15 & $0.68-$ \\
\hline & & & Control & 5 & 22.4 & 21 & 12.03 & 1 \\
\hline & & & $\begin{array}{c}\text { Total Research } \\
\text { Group }\end{array}$ & 14 & 23.07 & 25.5 & 10.4 & $0.04-$ \\
\hline \multirow{3}{*}{5} & \multirow{3}{*}{\multicolumn{2}{|c|}{$\begin{array}{l}\text { Measure Muscle strength of neck muscles, as long } \\
\text { as possible }\end{array}$}} & Experimental & 9 & 69.11 & 60 & 37.6 & 0.63 \\
\hline & & & Control & 5 & 45.8 & 45 & 18.57 & 0.3 \\
\hline & & & $\begin{array}{l}\text { Total Research } \\
\text { Group }\end{array}$ & 14 & 60.79 & 55.5 & 33.33 & 1.02 \\
\hline \multirow{3}{*}{6} & \multirow{3}{*}{\multicolumn{2}{|c|}{$\begin{array}{l}\text { Measure the muscle strength of the abdominal } \\
\text { muscles. Sit long from the dorsal position to make } \\
\text { with a } 90 \text { degree angle torso }\end{array}$}} & Experimental & 9 & 42.89 & 29 & 27.82 & 1.34 \\
\hline & & & Control & 5 & 77.2 & 90 & 28.62 & $1.24-$ \\
\hline & & & $\begin{array}{l}\text { Total Research } \\
\text { Group }\end{array}$ & 14 & 55.14 & 39.5 & 31.93 & 0.22 \\
\hline \multirow{6}{*}{7} & \multirow{6}{*}{$\begin{array}{l}\text { Measure the } \\
\text { muscular } \\
\text { strength of the } \\
\text { chest muscles }\end{array}$} & \multirow{3}{*}{ The right part } & Experimental & 9 & 6.11 & 5 & 5.46 & 1.5 \\
\hline & & & Control & 5 & 9.5 & 7.5 & 2.74 & 0.61 \\
\hline & & & $\begin{array}{c}\text { Total Research } \\
\text { Group }\end{array}$ & 14 & 7.32 & 6.25 & 4.85 & 1.52 \\
\hline & & \multirow{3}{*}{ The left part } & Experimental & 9 & 5.38 & 5 & 5.59 & 1.48 \\
\hline & & & Control & 5 & 8 & 7.5 & 2.09 & $0.51-$ \\
\hline & & & $\begin{array}{c}\text { Total Research } \\
\text { Group }\end{array}$ & 14 & 6.61 & 5 & 4.66 & 1.94 \\
\hline
\end{tabular}


Table 6 and the difference between the experimental group and the control group in the functional measurements before the experiment show that the value of (T) calculated between 0.03 to 0.74 and these values are not significant at level 0.05 indicating that there are no significant differences between the two groups And confirm that there is a parity between the research groups in the functional measurements before the experiment.
The difference between the experimental group and the control group in the physical measurements prior to the experiment shows that the calculated value $(\mathrm{t})$ is between 0.16 and 2.07. These values are not significant at 0.05 , indicating that there are no significant differences between the two groups and confirm that there is a parity between the two sets of research in physical measurements before the experiment [Table 7].

Table 6: Differences between the experimental group and the control group In functional measurements prior to the experiment (equivalence)

\begin{tabular}{|c|c|c|c|c|c|c|c|c|}
\hline \multirow{2}{*}{$\mathbf{N}$} & \multirow{2}{*}{\multicolumn{2}{|c|}{ Statistical Significance }} & \multicolumn{2}{|c|}{$\begin{array}{c}\text { The experiment } \\
\text { group } \\
\mathrm{N}=9\end{array}$} & \multicolumn{2}{|c|}{$\begin{array}{l}\text { Control group } \\
\qquad \mathrm{N}=5\end{array}$} & \multirow{2}{*}{$\begin{array}{l}\text { The difference } \\
\text { between the } \\
\text { two averages }\end{array}$} & \multirow{2}{*}{$\begin{array}{c}\text { Values } \\
\mathbf{T}\end{array}$} \\
\hline & & & $\mathrm{x}$ & $\Sigma$ & $x$ & $\Sigma$ & & \\
\hline 1 & \multicolumn{2}{|c|}{$\begin{array}{l}\text { The difference between the maximum } \\
\text { inhalation and the maximum exhalation }\end{array}$} & 2.11 & 0.93 & 2.2 & 0.84 & 0.09 & 0.18 \\
\hline \multirow{2}{*}{2} & RSPFLO device & inhalation & 966.67 & 200 & 1020 & 268.33 & 70.77 & 0.39 \\
\hline & $\begin{array}{l}\text { efficiency of the } \\
\text { respiratory system }\end{array}$ & exhalation & 811.11 & 220.48 & 900 & 212.13 & 88.89 & 0.74 \\
\hline 3 & \multicolumn{2}{|c|}{$\begin{array}{c}\text { Cardiac muscle strength( ultrasound scan on } \\
\text { the heart) }\end{array}$} & 65.11 & 6.58 & 65 & 7.78 & 0.11 & 0.03 \\
\hline
\end{tabular}

Table 7: Differences between the experimental group and the control group in physical measurements before the experiment (equivalence)

\begin{tabular}{|c|c|c|c|c|c|c|c|c|}
\hline \multirow{2}{*}{$\mathbf{N}$} & \multirow{2}{*}{\multicolumn{2}{|c|}{ Statistical significance }} & \multicolumn{2}{|c|}{$\begin{array}{l}\text { The experimental } \\
\text { group } \\
\mathrm{N}=9\end{array}$} & \multicolumn{2}{|c|}{$\begin{array}{l}\text { Control group } \\
\qquad \mathrm{N}=5\end{array}$} & \multirow{2}{*}{$\begin{array}{l}\text { The difference } \\
\text { between two } \\
\text { averages }\end{array}$} & \multirow{2}{*}{$\begin{array}{l}\text { values } \\
\qquad \mathrm{T}\end{array}$} \\
\hline & & & $\Sigma$ & $\mathbf{x}$ & $\Sigma$ & $x$ & & \\
\hline 1 & \multicolumn{2}{|c|}{$\begin{array}{l}\text { Measure the natural elasticity of the neck } \\
\text { muscles degrees } 10\end{array}$} & 8.72 & 2.22 & 9.40 & 1.34 & 0.68 & 0.71 \\
\hline 2 & \multicolumn{2}{|c|}{$\begin{array}{l}\text { Measure the natural elasticity of the chest } \\
\text { muscles. The arms are elongated, resting on } \\
\text { their } 180 \text { degrees }\end{array}$} & 179.11 & 1.83 & 180.00 & 0.00 & 0.89 & 1.45 \\
\hline 3 & \multicolumn{2}{|c|}{$\begin{array}{l}\text { Measure the natural elasticity of the } \\
\text { abdominal muscles (measuring the extent of } \\
\text { the movement of the torso in the spine) }\end{array}$} & 59 & 17.18 & 73.00 & 22.81 & 14 & 1.2 \\
\hline \multirow[t]{2}{*}{4} & \multirow{2}{*}{$\begin{array}{l}\text { Measure the } \\
\text { dynamic movement } \\
\text { of the spine around } \\
\text { the vertical axis }\end{array}$} & The right part & 19.33 & 15.26 & 15.40 & 9.04 & 3.93 & 0.61 \\
\hline & & The left part & 23.44 & 10.15 & 22.40 & 12.03 & 1.04 & 0.16 \\
\hline
\end{tabular}

Citation: Waleed Abd el Fattah Fahmy Mahmoud (2017) Physical Rehabilitation Program to Improve the Physical and Functional Page 10 of 17 Status after Hospitalization of Open-Heart Surgery. J Cardiovascular Thoracic Surgery 3(1):1-17. 


\begin{tabular}{|c|c|c|c|c|c|c|c|c|}
\hline 5 & \multicolumn{2}{|c|}{$\begin{array}{l}\text { Muscle strength of neck muscles, Stability as } \\
\text { long as possible }\end{array}$} & 69.11 & 37.60 & 45.80 & 18.57 & 23.31 & 1.55 \\
\hline 6 & \multicolumn{2}{|c|}{$\begin{array}{l}\text { Measure the muscle strength of the } \\
\text { abdominal muscles. Sit long from the dorsal } \\
\text { position to make with a } 90 \text { degree angle } \\
\text { torso }\end{array}$} & 42.89 & 27.82 & 77.20 & 28.62 & 34.31 & 2.07 \\
\hline \multirow[t]{2}{*}{7} & \multirow{2}{*}{$\begin{array}{l}\text { Measure the } \\
\text { muscular strength of } \\
\text { the chest muscles }\end{array}$} & The right part & 6.11 & 5.46 & 9.50 & 2.74 & 3.39 & 1.54 \\
\hline & & The left part & 5.83 & 5.59 & 8.00 & 2.09 & 2.17 & 1.04 \\
\hline
\end{tabular}

\section{Differences between the before measurement and the after measurement for the experimental group}

Table 8 and Figure 17 on the differences between the premeasurement and the telemetry in the functional measurements of the experimental group. There are differences between the tribal and the barometric measurements at level 0.05 in the measurement of the excitation and exhalation trip. The values ranged between 2.29 to 4.44 and these values were greater than the tabular value at 0.05 and the improvement rate ranged from $0.85 \%$ to $42.11 \%$.
Table 9 and Figure 15,16 on the differences between the premeasurement and the dimensional measurement in the physical measurements of the experimental group. There are differences between the tribal and the vertex measurements at 0.05 in the measurement of natural elasticity of the abdominal muscles, The spinal column around the vertical axis of the left and right sides of the chest, measuring the muscle strength of the neck muscles, measuring the muscle strength of the abdominal muscles, measuring the muscle strength of the left and right and left breast muscles. With a value ranging from 3.42 to 7.24 . These values are greater than the tabular value at 0.05 and the improvement rate ranged from $0.37 \%$ to $240.80 \%$.

Table 8: Differences between the before measurement and the after experimental measurement of the experimental group in functional measurements $\mathrm{N}=9$

\begin{tabular}{|c|c|c|c|c|c|c|c|c|c|c|}
\hline \multirow[t]{2}{*}{$\mathbf{N}$} & \multirow{2}{*}{\multicolumn{2}{|c|}{ Functional measurements }} & \multicolumn{2}{|c|}{$\begin{array}{l}\text { Measurements } \\
\text { before }\end{array}$} & \multicolumn{2}{|c|}{ Measure after } & \multicolumn{2}{|c|}{$\begin{array}{l}\text { The difference } \\
\text { between the two } \\
\text { averages }\end{array}$} & \multirow[t]{2}{*}{ Values $\mathbf{t}$} & \multirow[t]{2}{*}{$\begin{array}{l}\text { Improvement } \\
\text { rate } \%\end{array}$} \\
\hline & & & $\mathbf{x}$ & $\Sigma$ & $\mathbf{x}$ & $\Sigma$ & $\mathbf{x}$ & $\Sigma$ & & \\
\hline 1 & \multicolumn{2}{|c|}{$\begin{array}{l}\text { Journey of inhalation and exhalation, } \\
\text { the difference between maximum } \\
\text { inhalation and maximum exhalation }\end{array}$} & 2.11 & 0.93 & 1.22 & 0.44 & 0.89 & 0.6 & ${ }^{*} 4.44$ & 42.11 \\
\hline \multirow[t]{2}{*}{2} & \multirow[b]{2}{*}{$\begin{array}{l}\text { RSPFLO } \\
\text { device to } \\
\text { assess the } \\
\text { efficiency } \\
\text { of the } \\
\text { respiratory } \\
\text { system }\end{array}$} & Inhalation & 966.67 & 200 & 1077.78 & 148.14 & 111.11 & 145.3 & ${ }^{*} 2.29$ & 11.49 \\
\hline & & Exhalation & 811.11 & 220.48 & 866.67 & 132.29 & 55.56 & 101.38 & 1.64 & 6.85 \\
\hline 3 & \multicolumn{2}{|c|}{$\begin{array}{l}\text { Cardiac muscle strength( ultrasound } \\
\text { scan on the heart) }\end{array}$} & 65.11 & 6.58 & 64.56 & 4.56 & 0.56 & 8.34 & 0.2 & 0.85 \\
\hline
\end{tabular}

Citation: Waleed Abd el Fattah Fahmy Mahmoud (2017) Physical Rehabilitation Program to Improve the Physical and Functional Page 11 of 17 Status after Hospitalization of Open-Heart Surgery. J Cardiovascular Thoracic Surgery 3(1):1-17. 


\begin{tabular}{|c|c|c|c|c|c|c|c|c|c|c|}
\hline \multirow[t]{2}{*}{$\mathbf{N}$} & \multirow{2}{*}{\multicolumn{2}{|c|}{$\begin{array}{l}\text { Physical measurements } \\
\qquad \mathrm{x}\end{array}$}} & \multicolumn{2}{|c|}{$\begin{array}{l}\text { Measurement } \\
\text { before }\end{array}$} & \multicolumn{2}{|c|}{ Measure after } & \multicolumn{2}{|c|}{$\begin{array}{c}\text { The difference } \\
\text { between the two } \\
\text { averages }\end{array}$} & \multirow[t]{2}{*}{$\begin{array}{c}\text { Values } \\
\mathbf{T}\end{array}$} & \multirow[t]{2}{*}{$\begin{array}{l}\text { Improvement } \\
\text { rate } \%\end{array}$} \\
\hline & & & $\Sigma$ & $\mathbf{x}$ & $\Sigma$ & $\mathbf{x}$ & $\Sigma$ & & & \\
\hline 1 & \multicolumn{2}{|c|}{ Measure the natural elasticity of the neck muscles degrees 10} & 8.72 & 2.22 & 9.78 & 0.44 & 1.06 & 2.19 & 1.45 & 12.1 \\
\hline 2 & \multicolumn{2}{|c|}{$\begin{array}{l}\text { Measure the natural elasticity of the chest muscles. The arms are } \\
\text { elongated, replacing their integrity. Degree } 180\end{array}$} & 179.11 & 1.83 & 179.78 & 0.44 & 0.67 & 1.8 & 1.11 & 0.37 \\
\hline 3 & \multicolumn{2}{|c|}{$\begin{array}{l}\text { Measure the natural elasticity of the abdominal muscles (measuring } \\
\text { the extent of the movement of the torso in the spine) }\end{array}$} & 59 & 17.18 & 86.56 & 14.05 & 27.56 & 14.13 & *5.86 & 46.7 \\
\hline \multirow[t]{2}{*}{4} & \multirow{2}{*}{$\begin{array}{l}\text { Measure the dynamic movement of the spine } \\
\text { around the vertical axis }(\mathrm{N}) \text { from } 0 \text { to } 75 \mathrm{~cm} \text { on } \\
\text { staging }\end{array}$} & The right part & 19.33 & 15.26 & 65.89 & 24.12 & 46.56 & 19.3 & 7.24 & 240.8 \\
\hline & & The left part & 23.44 & 10.15 & 66.89 & 22.21 & 43.44 & 19.88 & *6.56 & 185.31 \\
\hline 6 & \multicolumn{2}{|c|}{$\begin{array}{l}\text { Measure the muscle strength of the abdominal muscles. Sit long } \\
\text { from the dorsal position to make with a } 90 \text { degree angle torso }\end{array}$} & 42.89 & 27.82 & 90 & 0 & 47.11 & 27.82 & *5.08 & 109.84 \\
\hline \multirow{2}{*}{7} & \multirow{2}{*}{$\begin{array}{l}\text { Measure the muscular strength of the chest } \\
\text { muscles }\end{array}$} & The right part & 6.11 & 5.46 & 11.89 & 6.01 & 5.78 & 5.08 & "3.42 & 94.55 \\
\hline & & The left part & 5.83 & 5.59 & 12.11 & 5.62 & 6.28 & 5.14 & "3.66 & 107.62 \\
\hline
\end{tabular}

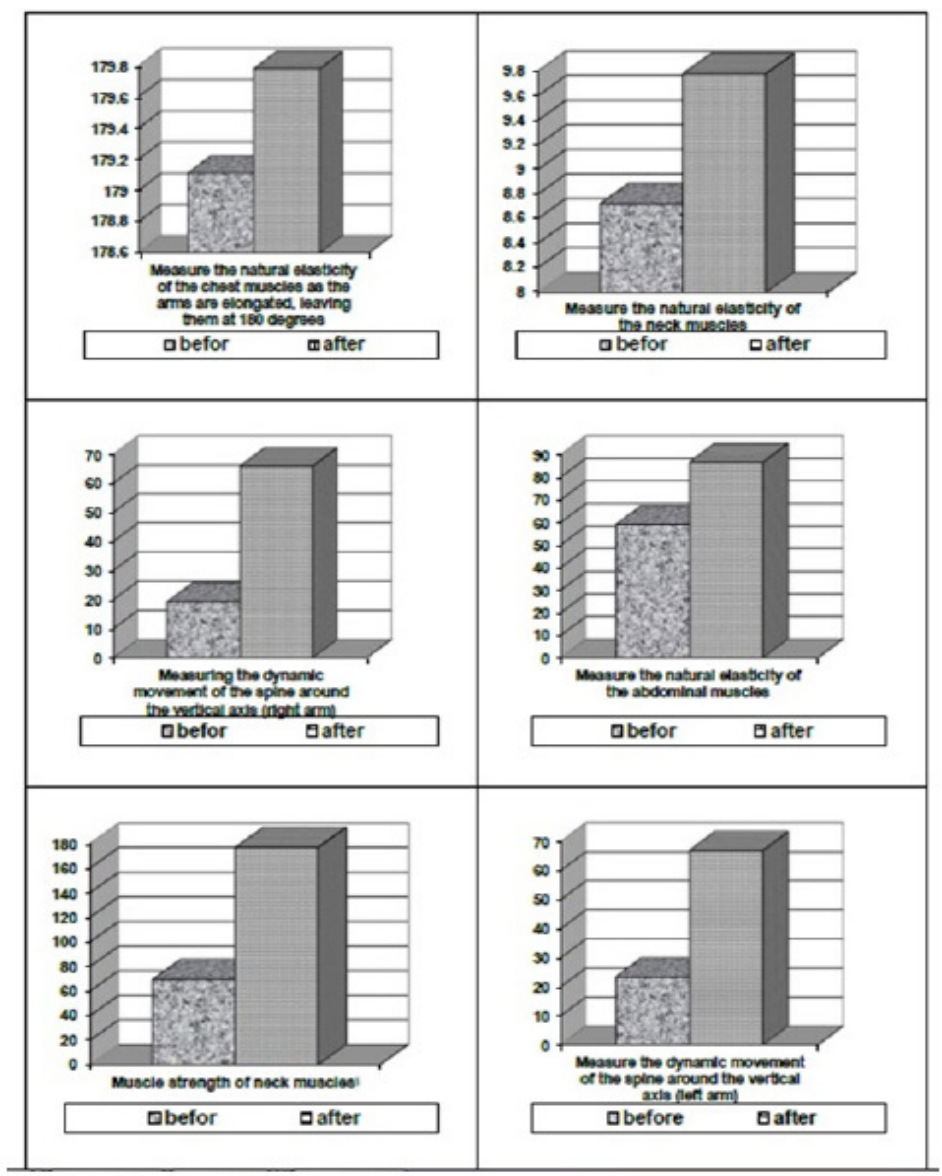

Figure 15: The arithmetic mean of the Before measurement and the after measurement of the dimension of the experimental group In (physical measurements -1)

Citation: Waleed Abd el Fattah Fahmy Mahmoud (2017) Physical Rehabilitation Program to Improve the Physical and Functional Page 12 of 17 Status after Hospitalization of Open-Heart Surgery. J Cardiovascular Thoracic Surgery 3(1):1-17. 


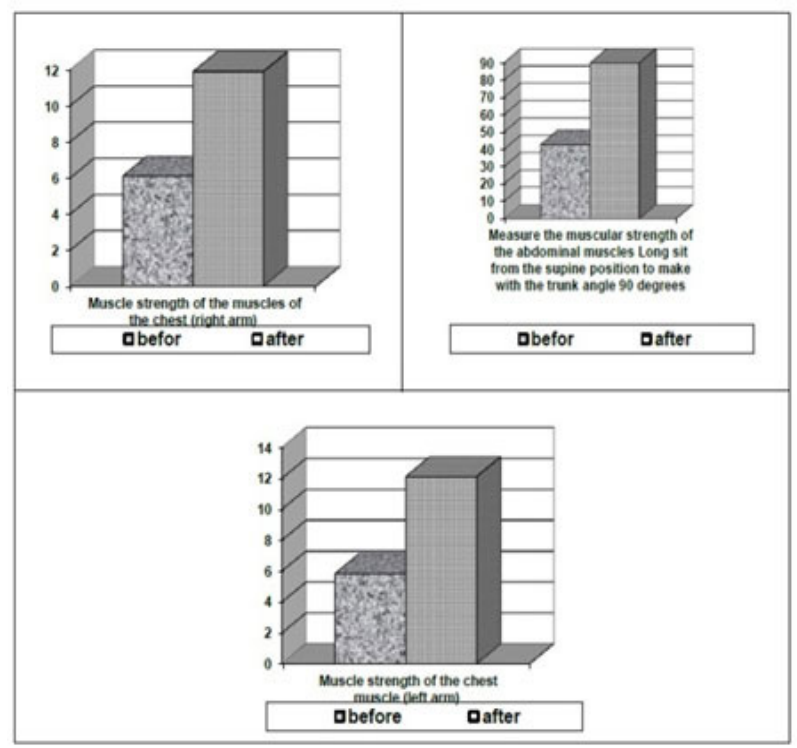

Figure 16: The arithmetical meaning of the measurement before and the measure after of the experimental group In (physical measurements- 2)

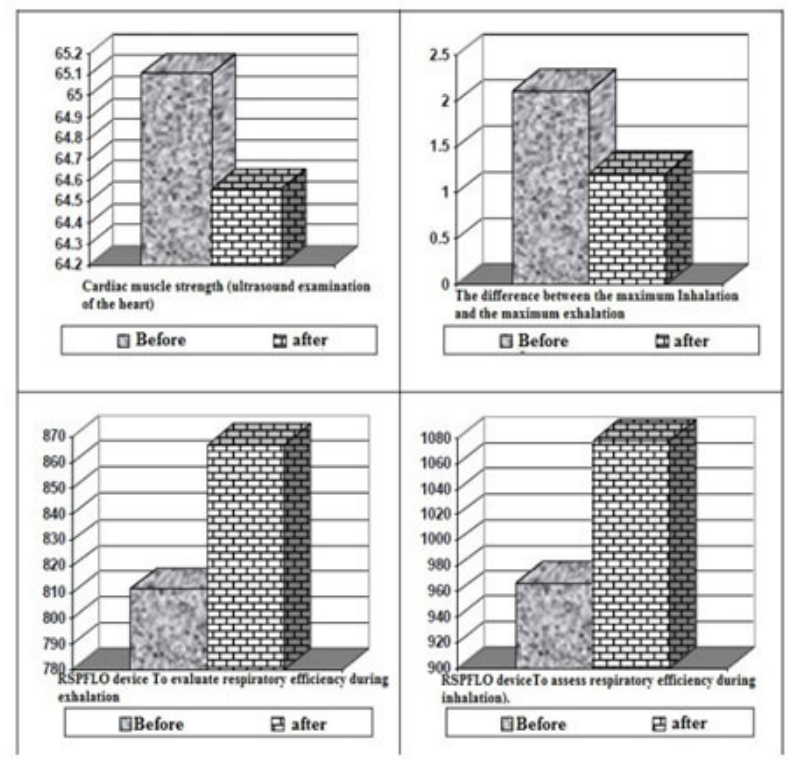

Figure 17: The arithmetic mean of the measurement before and the measure after of the experimental group In (functional Measurements).

\section{Discussion}

There are significant statistical significance differences between the tribal and tertiary measurements of the program in the experimental research group in favor of tribal measurement, where the value of 4.44 was improved by $42.11 \%$ and attributed the researcher to the wearing of heavy clothing group members where the tribal measurement was applied in the winter and most of the members of the group of women and it was difficult in this conservative society to remove women's clothes to apply the test correctly and at the end of the program was the measurement for most of the group in the spring where clothes This is where the difference occurs. And, of course, the respiratory efficiency of patients decreases after open heart surgery and once out of intensive care and gradually increases with rehabilitation according to the responsiveness and ability of each individual patient Measurement (2) is shown in table 8 for measurement of respiratory efficiency. There were statistically significant differences between the pre-test and the pre-test in the experimental group for the benefit of the post-suction during the suction, where the value of 2.29 was improved by $11.49 \%$. The situation differed during the blowing. There were differences not significant but also for the dimension of dimension, an improvement of $6.85 \%$.

And attributed the researcher to the ability of members of the group to exchange the inhalation and exhaling well, and this is why the start of the group in the process of inhalation and exhale immediately after their departure from intensive care. As well as physical pregnancy on the respiratory system as a result of weight training.

And the researcher attributed the decrease in the rate of improvement during blowing out during the suction that the nature of this device designed for training on suction and to withdraw the maximum amount of inhalation on the scale of the ball machine (Rsfllo). But the researcher uses it in an innovative way that allows it to be used during the blowing process and to remove the maximum exhalation after turning the device down. During this process, the resistance increases and the device needs a larger force and a larger volume of air that is pumped from the device's apparatus to move the balls on the staging and thus increase the degree of difficulty during performance.

According to Janat Darwish, Sana Abdulsalam (2007), the efficiency of breathing is due primarily to the efficiency of pulmonary ventilation between the alveoli in the lungs and blood in the capillaries where the exchange of oxygen and carbon dioxide and this process depends on the balance between air pressure in and out The lungs are caused by the contraction of the diaphragm muscles and the work of the muscles between the ribs, which helps constriction of the circumference of the circumference of the rib cage and thus increase the capacity of the lungs, which leads to the pressure drop them and pull the air inside to complete the process of inhalation, while exhaling relaxes the muscles that seized During the inhalation, the rib cage returns to its original size and pressure rises inside the chest and the air is expelled outward [16].

Mohamed Sobhi Hassanein (2004) states that the vital capacity reflects the safety of the body's respirators and is very much related to the skills that require periodic circulatory skin and reflect the physiological efficiency. Individuals with a high level of vitality may become high-level and make significant progress [19].

Hazza Mohammed Hazza (1992) found that the primary function of the lungs lies in the supply of oxygen to the blood and the elimination of carbon dioxide. It is accomplished through the 
mechanical breathing process, which is the contraction of the respiratory muscles [29].

Abdel Moneim Badir Al-Qusair (2008) points out that the respiratory system is one of the most important devices that can accurately control the intensity of the physical effort on the individual. The relationship is related to the high intensity of the breathing process with the increase in the intensity of the physical effort [2].

Measurement (3) is shown in table 8 for measuring the strength of the heart muscle. There were statistically significant differences between the pre-test and the pre-test for the experimental group in favor of tribal measurement, where the value of 0.20 was $0.85 \%$.

The researcher believes that this is due to the decline of strength of the heart muscle after surgery immediately before the value of the surgery and then begins to increase gradually with the application of the program, and therefore must be done ultrasound examination on the heart immediately after surgery.

Ezzat Mahmoud Al-Kashif (1990) states that practicing different types of exercise and sports is one of the most effective and effective means of training the heart muscle; Physical exercise is an appropriate means for the work of all internal organs, especially heart function. , And that the heart muscle during physical work becomes stronger [15].

Abdul Raziq Yousuf Ibrahim (2009) points out that sports training has a positive effect on physical fitness and shows a clear effect on the increase of heart muscle and cardiac momentum [3]

Many researchers agree that regular physical activity and participation in sports training programs lead to changes in the heart muscle and include anatomical changes in heart size and weight $[11,30]$.

Patrick 0'She emphasizes that bodybuilding promotes muscular endurance, cardiovascular, and fitness and cardiovascular improvement is associated with choice of exercise, intensity training, and duration of rest periods between exercise groups [6].

Ramin Shabani, et al. also mentions that rehabilitation improves the ability to exercise and provide oxygen to the heart muscle [21].

Takahiro Sumide \& Kazunori Shimad the previous studies have shown that the use of exercise for cardiac rehabilitation improves muscle strength in patients with myocardial infarction and patients after heart surgery, according to [24].

Thus, the third question is answered. Are there any significant differences in the functional measurements under study for the thoracic muscle injury affected by surgery before and after the program of the experimental group?

As well as the fifth question, which provides for whether there are differences of statistical significance in the efficiency and strength of the heart muscle before and after the program of the experimental group?
It is clear from the measurement number (1) in table 9. There is a statistically significant difference between the pre-test and the test score in the experimental group for the benefit of telemetry, where the value reached 1.45 , an improvement rate of $12.10 \%$. The ability of the program to help restore the natural elasticity of neck muscles after surgery is excellent.

As shown in table 9 for the measurement of natural elasticity of the chest muscles, there are statistically significant differences between the pre-test and the test scores in the experimental group for the benefit of telemetry, where the value of 1.11 was improved by $0.37 \%$. There is a very slight decrease in the group and this decrease does not indicate a decrease in rubber, but recorded slight differences at the normal level of tribal measurement and this decline disappeared definitively in the measurement of dimension and this indicates the extent of the program to restore the natural rubber of the muscles of the chest and overcome the percentage of very slight decrease Group D in the measurement of tribal and natural rubber return to the muscles of the chest are excellent.

It is also evident from the measurement (3) in table 9 for the measurement of natural elasticity of the abdominal muscles. There are significant differences of statistical significance between the pre-test and the test of the program in the experimental group for the benefit of telemetry, where the value of 5.85 reached an improvement rate of $46.70 \%$. Significant and noticeable in the natural elasticity of the abdominal muscles is due to the success of the program and its ability to increase the natural elasticity of the abdominal muscles, one of the muscles affected by the operation [4]. In table 9 to measure the dynamic movement of the spine around the vertical axis. There were significant differences between the tribal and the subnetting of the program in the experimental group for the benefit of telemetry in the right and left side of the chest the value on the right margin reached 7.24 with an improvement of $240.80 \%$ and the value of the left segment was 6.56 with an improvement rate of $185.3 \%$.

And that this shows that the increase of natural rubber of the muscles of the chest in the experimental group after the application of the program from the normal before the surgery and that exceeded the normal ratio of the measurement of $0-75 \mathrm{~cm}$ on the staging of both left and right sides. Is one of the strongest signs of complete healing of the shear bone.

In this regard, some studies suggest that when using stretching exercises for several weeks, this leads to a permanent increase in the elasticity of the muscle group involved in the movement [9].

It also suggests that deep breathing exercises promote full lung expansion, relieve muscle spasm, and work to remove lung secretions. , Expand chest and improve shoulder function.

Gordon Waddington \& Roger Adams (2007) note that exercise improves muscular function, contrary to the common belief that movement should be avoided to avoid pain [12].

The number of measurements in table 9 for the measurement of muscular strength of the neck muscles is shown in table 9. And 
the researcher attributed this to the ability of patients to hold a longer period of telemetry than in the tribal measurement and this indicates the effectiveness of the program and its ability to raise the efficiency of muscle strength of the muscles of the neck a very large difference from the tribal measurement of the experimental group.

Where immediately after surgery and immediately after intensive care, the muscles of the neck began to move and the contraction of the neck muscles began in succession.

And in advanced stages of the program, the patient performed neck exercises against the resistance of the hand of the processor and this in turn led to the achievement of this result and the high rate of improvement from tribal measurement.

Measurement (6) is shown in table 9 for measuring the muscular strength of the abdominal muscles. There were significant differences with statistical significance between the tribal measurement and the program subdivision in the experimental research group for the benefit of telemetry, where the value of 5.08 reached an improvement rate of $109.84 \%$.

And the researcher pointed out that most of the members of the group were non-practitioners of sport and therefore it was difficult to perform this test in the tribal measurement and with the subject of the group members of the program and their continuation regularly and start the work of constant contractions of the muscles of the abdomen once out of intensive care and start the process of inspiration and exhalation In the process of exhalation and in advanced stages of the program was increased muscle contractions of the muscles of the abdomen and pressure on the muscles, which increased the ability of the muscles to work more efficiently than before the surgery.

Zakia Ahmed Fathi et al. note that when comparing the great force resulting from constant muscular contractions with those resulting from mobile muscular contraction, we observe the superiority of the fixed force on the motor. If increased resistance increases the number of muscle fibers involved in contractions and therefore the constant force is always accompanied by the involvement of a larger number of muscle fibers. , And organized sports training increases the efficiency of the muscular system [28].

There are significant differences between the pre-test and the pre-test measurements of the experimental group for the benefit of telemetry in the right side of the chest, where the value of $3.42 \% 94.05 \%$ improvement. The value of the left ventricle of the chest was 3.66 with an improvement rate of $107.62 \%$. This indicates an increase in the muscle strength of the chest muscles in the experimental group after applying the rehabilitation program before surgery.

And the researcher attributed this to the use of the first time weight training at an advanced stage of the program in addition to the speed of starting the work of muscle contractions of the muscles of the chest as well as accelerates the start of the process of exchange of inspiration and exhalation.
The researcher also attributes the slight differences in measurement and improvement rates between the right and left segments in favor of the left side to the individual differences between the group members and their response, as well as the severity of the weakness resulting from the operation and its impact on the members of this group.

Mark a. Williams, et al. that weight training increases muscle strength and endurance, and the ability to perform a wide range of activities. It reduces disability and enhances the quality of life. It also works to increase bone mineral density and lean body mass [18].

The American Heart Association points out that weight training increases health and fitness [28].

The answer to the fourth question of the research was to determine whether there are differences of statistical significance in the physical measurements represented in the strength and elasticity of muscles affected by surgery before and after the program of the experimental group?

To answer the first question, does the program speed up the process of healing the shear bone after open heart surgery compared to the control group? And the second question, which determines whether the program will reduce the pain experienced by the patient compared to the control group? The shear bone was examined electronically for each sample by measuring the shear bone on the entire length from top to bottom as well as on both sides of the bone. And the clinical examination has shown no pain at the end of the program period, indicating the complete healing of the shear. This is due to the therapeutic features of the program, such as some physiotherapy equipment (tens current, -laser-therapy, ultrasound-therapy), as well as rehabilitation exercises that have greatly affected the speed of recovery of patients after open heart surgery in the shortest time Maybe.

Jan Magnus Bjordala, et al. note that there is documented evidence that tens current reduces pain within the first 3 days after surgery [17].

Prentice William, \& Jaskoviak Paul suggests that the use of ultrasound works to stretch tissues, reduce pain and convulsions, increase blood flow and metabolic rate, which in turn leads to improved healing [7].

Grace Wang notes that low-level laser works to relieve pain, reduce tension and improve functional capacity [13].

And the researcher was unable to answer the sixth question, which provides for whether there are differences of statistical significance in the functional and physical measurements in question after the program between the experimental and control groups? Because the researcher cannot perform functional and physical measurements of the control group after the expiry of the period specified for application of the program to members of the experimental group due to lack of healing bone shear in the control group during this period. , And thus the risk that shears bone may be exposed in the case of such measurements before they are cured. Where the results of measurements on all 
members of the experimental group to degree of pain $=0$ and the degree of healing $100 \%$, and showed no measurements of varying degrees of measurement.

\section{Conclusions}

In light of the objectives of the research and the framework of the scientific method used and through the presentation and discussion of the results reached the researcher the following conclusions

-The disappearance of the patient's pain and the healing of the shear bone during the first three weeks of surgery following the exit from intensive care.

-Physiotherapy (TensCurrent-laser-ultrasound) has a significant effect on the healing of the shear bone and the disappearance of pain within the first three weeks immediately after surgery.

-Natural rubber back of the neck muscles.

-Natural rubber return to the muscles of the chest.

-Significant and noticeable increase in the natural elasticity of the abdominal muscles after application of the program compared to the normal state of the patient before the surgery.

-Increase the dynamic movement of the spine around the vertical axis in the experimental group after the application of the program from the normal before the surgery, where the normal ratio of the measurement from 0 to $75 \mathrm{~cm}$ on the staging of both arms. -Increase the dynamic movement of the spine around the vertical axis in the right side of the chest to the left of it.

-Increase the strength of muscle strength of the neck muscles by a very large difference from the tribal measurement of the experimental group.

-Increase the strength and efficiency of abdominal muscles in the experimental group compared to tribal measurement.

-Increase the muscle strength of the muscles of the chest in the experimental group after the application of the rehabilitation program before the surgery.

-The high percentage of improvement in the muscle strength of the left part of the chest in the right part.

-Improves the efficiency of the respiratory system during the process of suction and blowing on the ball machine with an increase in the rate of improvement during the suction process during the process of blowing after the application of the program compared to the tribal measurement of the experimental group.

-The rehabilitation program can increase the strength and efficiency of the heart muscle.

-The strength of the heart muscle decreases immediately after surgery and gradually increases with application of the program at varying rates.

- There was no improvement in the control group as the shear bone did not heal during the period of application of the program to the experimental group, which lasted for one month immediately after surgery.
-Measurements cannot be taken by members of the control group after one month and one week from the date of exit from intensive care due to the severity of the shear bone, which may cause a hernia in surgery.

\section{Recommendations}

-The program should be implemented as soon as the patient is out of intensive care gradually.

-The use of physiotherapy equipment (tens current - laser ultrasound) on patients after open heart surgery.

-The correct placement of the electrode as shown in the research procedures should be adhered to in order to obtain the best results and avoids any problems that may occur from the wrong situation of electrodes or lack of desired result.

-Start using the physiotherapy equipment according to each case to the extent and stability.

-The patient can gradually begin to carry weights and weights after three weeks of surgery during the application of the program.

-Perform ultrasound evaluation immediately after surgery to determine the weakness of the heart muscle strength.

-The application of the rehabilitation program subject to research because of its effectiveness in the rehabilitation of patients after open heart surgery and its ability to return patients as soon as possible to exercise their normal life and without problems compared to other programs that need more time to start implementation or to complete the implementation.

-Application of this program to all patients with open heart surgery, whether the valves or arteries or a hole in the heart or congenital defects.

-Apply this program to all surgeries that use the same surgical aperture in surgery.

\section{General Recommendations}

- The name of the diagnosis of such cases that are applicable to the problem of research and this type of surgery, Egypt cardiac rehabilitation (short ECR)) because of the difference between them and cardiac rehabilitation (CR) cardiac rehabilitation is common among the masses of specialists in this area.

-The patient can drive the car and go to work after three weeks of surgery during the application of the program.

- The patient can sleep on both sides alternately without any problems or pain less after three weeks of surgery during the application of the program.

\section{References}

1. Ahmed Mohamed Khater. Measurement in the field of sports. Dar Al Ma'arif; 1984.

2. Abdel Moneim Badir Al-Qusair. Physiology of Sport. Alexandria; 2008. 
3. Abdul Razek Yousif - Ibrahim Bayoumi. The Effect of Rehabilitation Exercises on the Physical Fitness of Patients with Cerebral Palsy Resulting from Cerebral Palsy-PhD Thesis. Department of Health Materials -Faculty of Physical Education for Boys: Banha University: 2009.

4. Williams MA, Haskell WL, Ades PA, Amsterdam EA, Bittner V, Franklin BA, et al. Resistance exercise in individuals with and without cardiovascular disease: 2007 update: a scientific statement from the American Heart Association Council on Clinical Cardiology and Council on Nutrition, Physical Activity, and Metabolism. Circulation. 2007;116(5):572-584.

5. British Heart Foundation. Having heart surgery-British Heart Foundation registered charity in England and Wales (225971) and in Scotland (SC039426); 2013.

6. Patrick O'Shea. Iron heart. Journal of purepower;2004.

7. Prentice William, Jaskoviak Paul. Therapeutic Ultrasound. Chapter 4 Physiological Therapeutics. New York Chiropractic College; 2003.

8. Caspersen, Powell. Physical Activity, Exercise, and Physical Fitness Definitions and Distinctions for Health -Related Research. Public Health Reports, March-April 1985, Measurement in the field of sports - Dar Al Ma'arif 1984

9. Damien Howell. Muscles and stretching. damien howell physical therapy, patterson ave and gaskins road (the old ukrops store); 2003.

10. Florence Peterson, Eliza Beth kemdall. Muscles testing and function. third edition. Lippincott Williams and Wilkins; 1983. p. 326.

11.flecksj, kraemerwj. Designing resistance training programs. 2nd ed. human kinetics, New York; 1997

12.El-Ansary D, Waddington G, Adams R. Trunk stabilization exercises reduce sternal separation in chronic sternal instability after cardiac surgery: a randomized cross-over trial. Aust J Physiother 2007;53(4):255-260.

13. Grace Wang. Low Level Laser Therapy (LLLT). Technology Assessment, Office of the Medical Director Department of Labor and Industries 2004

14. Health Sciences Foundation. The path to recovery after heart surgery. The regional cardiac and vascular patient education committee hamilton health sciences. st. joseph's healthcare: Hamilton; 2006. p. 5445

15.Izzet Mahmoud al-Kashif. Rehabilitation exercises for athletes and heart patients. Library of the Egyptian Renaissance: Cairo;1990.

16.Jannat Darwish, Sana Abdel Salam. Physiology of Sport. Sixth Edition Faculty of Physical Education for Boys in Abu Qir. Alexandria;2007.
17. Bjordal JM, Johnson MI, Ljunggreen AE. Transcutaneous electrical nerve stimulation (TENS) can reduce postoperative analgesic consumption. A meta-analysis with assessment of optimal treatment parameters for postoperative pain. Eur J Pain. 2003;7(2):181-188.

18.Williams MA, Haskell WL, Ades PA, Amsterdam EA, Bittner V, Franklin BA, et al. Resistance exercise in individuals with and without cardiovascular disease: 2007 update: a scientific statement from the American Heart Association Council on Clinical Cardiology and Council on Nutrition, Physical Activity, and Metabolism. Circulation. 2007;116(5):572-584.

19. Mohamed Subhi Hassanein. Measurement and Evaluation in Physical Education and Sports. Sixth Edition. Cairo: Arab Thought House; 2004

20. Mohamed Fathi Hindi. Medical Anatomy of Athletes, Arab Thought House. 1991.

21. Ramin Shabani, Gaeini AA, Nikoo MR, Nikbackt H, Sadegifar M. Effect of cardiac rehabilitation program on exercise capacity in women undergoing coronary artery bypass graft in hamadan-iran. Int J Prev Med. 2010 Fall;1(4):247-251.

22. Samia Khalil. Sports Injuries and Means of Treatment and Rehabilitation. 2006.

23. Secretariat of Medical Centers Specialized: Nasser Institute for Research and Therapy. Egypt - Cairo, Corniche of the Nile, Shoubra. 2006 AD.

24. Takahiro Sumide, Kazunori Shimada, Ohmura H, Onishi T, Kawakami $\mathrm{K}$, Masaki Y, et al. Relationship between exercise tolerance and muscle strength following cardiac rehabilitation: comparison of patients after cardiac surgery and patients with myocardial infarction. J Cardiol. 2009;54(2):273-81. doi: 10.1016/j.jjcc.2009.05.016

25. Thomassv Bilfinger, Toddk Rosengart. A patient guide to cardiothoracic surgery. Stony Brook University /SUNY, Produced by the Office of Communications; 2009.

26. William A Baumgartner, Duke E. Cameron: Cardiac Surgery A guide for patients and their families. Johns Hopkins University; 2009.

27.Wong, Bozinovski. Before, during and after your Heart Surgery. Vancouver Island health authority: Heart health program; 2011.

28. Zakia Ahmed Fathi. Physiology, Al-Ghad Press; 2000.

29. Hazaa Mohammed Hazza. Laboratory Experiences in the Functions of Physical Effort Members, Deanship of Library Affairs, King Saud University; 1992.

30. Bahaa Eddin Ibrahim Salama. Physiology of Sport. Second Edition. Cairo: Arab Thought House; 1994. 